\title{
The management of released hostages
}

\section{Keron Fletcher}

Hostage situations differ greatly - in the aims and goals of the hostage-takers, the frequency and intensity of maltreatment, the type and quality of conditions, the duration of captivity, and the processes by which they are ultimately resolved and concluded. Although there is a paucity of research-based data about hostage reactions, clinical management, and outcome, there are general descriptive accounts in the medical and popular literature. A number of key texts are highlighted in the references, and examples of different conditions are briefly summarised in Box 1 .

The psychiatric treatment of hostages and their relatives does not differ substantially from the psychiatric treatment of other victims of trauma, although management is inevitably affected by intense media, public and political interest. Since the subject of treatment for victims of trauma has already received attention in this journal (Adshead, 1995) it will not be covered in detail here. This article will focus upon descriptions of general and specific reactions seen in hostages, and on two forms of post-release management given to different groups of hostages.

\section{Hostage reactions in captivity}

Early psychological reactions after being kidnapped are predominantly anxiety-based, and are summarised in Table 1. Levels of hyperarousal can be sufficient to block or diminish pain perception. Individuals may be unable to comprehend the reality of their situation, and may have a markedly inaccurate sense of the passage of time, and a lack of awareness of the need for sleep or food.

Hostage A, a prison officer, was kicked in the head, back, ribs, and testicles, but although he could "see" what was happening he could not feel it, or if he felt it, it did not hurt. (Hillman, 1981)

In a study of 28 hostage victims, Siegel (1984) reported a $25 \%$ incidence of visual or auditory hallucinations associated with conditions of

\begin{tabular}{|l|}
\hline $\begin{array}{l}\text { Box 1. Examples of conditions following a } \\
\text { hostage-taking incident }\end{array}$ \\
Initial rapid, violent action \\
Noise, gunshot, screams, panic, smoke, \\
injuries, deaths \\
Sudden separation from family and friends \\
under frightening circumstances \\
Relative sensory deprivation \\
Visual: blindfolds, hoods \\
Tactile: ties, chains, handcuffs, restricting \\
movement \\
Auditory: solitary confinement or imposed \\
silence \\
Cell conditions \\
Cramped e.g. wardrobe, hole in the ground; \\
hazardous e.g. fuelled-up aircraft, mili- \\
tary target \\
Subject to temperature extremes \\
Poor hygiene, restricted access to toilets and \\
washing facilities \\
Low quality, monotonous food \\
Frequent illness, with little or no medical \\
treatment \\
Beatings, torture, mock executions, rape \\
Forced to witness maltreatment of loved \\
ones \\
Fear of inappropriate action or dialogue \\
from authorities or fellow hostages \\
Pervasive fear of death, exacerbated by \\
waves of terror \\
\end{tabular}

isolation, visual deprivation, restraint of physical movements, physical abuse, and threat of death. Hallucinations did not occur unless isolation and the threat of death were both present. Many of the

Keron Fletcher was a Consultant Psychiatrist in the Royal Air Force until 1994. His work involved assessing and treating Prisoners of War and Lebanese hostages. He now works for Shropshire's Mental Health NHS Trust. 


\section{Table 1. Examples of difficulties faced by hostages during period of captivity}

\begin{tabular}{|c|c|c|}
\hline Time & Common & Possible \\
\hline $\begin{array}{l}\text { Early (hours or days) } \\
\text { Anxiety-based } \\
\text { symptoms may recur } \\
\text { during breakdown } \\
\text { of hostage situation }\end{array}$ & $\begin{array}{l}\text { Subjective symptoms: } \\
\text { Terror or 'numbing' of mind, distorted time sense, } \\
\text { loss of pain sensation } \\
\text { Autonomic symptoms: } \\
\text { Dry mouth, uncontrollable trembling, loss of sphincter } \\
\text { control, fainting/falling asleep, loss of appetite } \\
\text { sleeplessness. } \\
\text { Impaired behavioural control: } \\
\text { Inability to move limbs, inability to speak, aimless } \\
\text { overactivity, unquestioning obedience, fatalistic } \\
\text { non-cooperation }\end{array}$ & $\begin{array}{l}\text { Hostage identification } \\
\text { syndrome } \\
\text { Hallucinations: } \\
\text { visual, auditory, tactile }\end{array}$ \\
\hline $\begin{array}{l}\text { Intermediate } \\
\text { (weeks or months) }\end{array}$ & $\begin{array}{l}\text { Continuing psychological shock; continuing fear of } \\
\text { death; anger; grief; developing resignation }\end{array}$ & Paranoid reactions \\
\hline $\begin{array}{l}\text { Late } \\
\text { (months or years) }\end{array}$ & $\begin{array}{l}\text { Development of variety of coping strategies; periods } \\
\text { of relative normality; tedium; despair; depression; } \\
\text { emotional lability with raised and dashed hopes }\end{array}$ & Suicide attempts \\
\hline
\end{tabular}

hallucinations were complex, similar to those reported in near-death experiences. Hostages described sensations of floating out of their bodies, travelling down tunnels, and seeing bright, vivid figures of familiar people. The experience sometimes had deep religious significance.

Hostage B, a 61-year-old grandmother, was kept gagged and bound for 4 days in a dark wardrobe. She experienced visual hallucinations of coloured patterns and holiday scenes, and thought that she was in a train tunnel, perceiving the wardrobe doors to be a long distance away. She felt invisible at one point, and had an experience of floating through the wardrobe doors and around her house. When released she estimated that she had been held for 2 days. (Siegel, 1984)

In the absence of other symptoms and signs these hallucinations do not herald the onset of mental illness, and usually resolve spontaneously. However, severe psychotic reactions can develop in vulnerable individuals (Weschler, 1990), or be exacerbated by lack of medication.

At the time of his kidnapping hostage $C$ was suffering from schizophrenia. He received no treatment, and spent the entire period of his one year captivity in a florid psychotic state. He was chained throughout to another Western hostage.

Religious faith has been reported by many hostages as strengthening and sustaining. This has been of great importance to some, and has altered the course of their lives on release. Conversely, a minority abandon religious values in the face of their adversity, or feel envy towards those for whom prayer and faith provide support (Ayalon, 1982; Weschler, 1990; Anderson, 1993).
The release of hostages may coincide with hostile action and an acute exacerbation of anxiety-based symptoms.

\section{Difficulties for those left behind}

It is usual for relatives and friends to experience marked anxiety and anger immediately after a kidnapping. For a number of days they may search for the hostage, if his location is unknown. Prolonged hostage situations may precipitate serious financial difficulties, depression and substance misuse. Some relatives and friends shun campaigning, believing that sufficient is being done to secure release and from concern that raising a hostage's profile might increase their value as a captive. Others put considerable time and energy into campaigns, publicising the hostage's plight in order to raise awareness and keep the situation on the political agenda. Either stance may contribute to post-release readjustment difficulties, as some blame themselves for not having done enough, and others learn to give up new-found prominence.

\section{Post-release problems}

\section{General difficulties}

The normal immediate reaction to release is elation and optimism, but this may be accompanied by emotional lability, with periods of excitement and 
loquacity alternating with withdrawal, exhaustion, and bewilderment.

New anxiety-related symptoms are very common in those released from a brief ordeal, being reported in $94 \%$ of 168 released Dutch hostages within the first four weeks, falling to two-thirds after four weeks (Stöfsel, 1980). At one to three years post-release symptom intensity tends to be greater in women, the young, the less well educated and in those held captive the longest. Family members report similar but less severe symptoms. Van der Ploeg \& Kleijn (1989) followed up 138 hostages and their families for six to nine years, at which point $12 \%$ of hostages and $11 \%$ of family members were regarded as still requiring professional help. Although negative effects decreased over time, anxiety, tension and sleeping problems were still common, and psychosomatic complaints had increased in both hostages and family members.

Easton \& Turner (1991) followed up 381 hostages four to five months after their release. Many of these hostages were used as a 'human shield', strategically held near potential military targets in Kuwait and Iraq in order to deter Allied Forces from attacking them. Nearly half of the hostages suffered physically from a range of problems including untreated bacillary and amoebic dysentery, giardiasis, and lack of medication. During detention individuals reported poor concentration, indecisiveness, and bizarre behaviour in those who were previously stable. Over half felt guilty to be home alive and well, and $10 \%$ blamed themselves for getting caught up in the situation.

On the 28-item General Health Questionnaire (GHQ; Goldberg \& Hillier, 1979) 27\% exceeded the conservative cut-off point (scores $>12$ ) and $49 \%$ scored more than two standard deviations above the mean on the Impact of Events Scale (IES; Horowitz et al, 1979). Elevated GHQ scores were associated with present losses, such as loss of property, loss of job, serious financial and accommodation problems secondary to the war. Present losses were also associated with increased IES scores, as were threat events experienced during detention, such as thinking they or someone close to them might be killed, witnessing fighting, receiving personal threats, experiencing violence, seeing civilians threatened or someone being killed. Scores on the Attitude Change Index (a questionnaire examining lasting changes in priorities, feelings of being different from, or misunderstood by, other people, and alterations to political views or religious beliefs; Easton \& Turner, 1991) were also most highly correlated to the experience of threat, followed by loss events in the Gulf. Of the married subjects $146(47 \%)$ reported an impact upon their marriage. Twenty-three per cent experienced a strengthening of the marital relationship, but $22 \%$ had difficulties including poor communication and loss of libido. Two-thirds of parents said that their children had been affected, with $49 \%$ describing nightmares, fear of uniforms, nocturnal enuresis, 'attention-seeking behaviour', and impaired school performance. Many children were frightened of letting their parents go abroad again.

Hostages who endure years in captivity show additional features shortly after release. The first social encounters with family and friends may be approached with apprehension. Patterns of behaviour employed during captivity may persist, such as reaching for a blindfold when a door opens, remaining unaware of conventional standards of dress or normal time constraints. Sleeping and eating patterns can be difficult to re-establish. Physical problems may be severe or unexpected, for example depressed skull fractures with epilepsy or permanent neurological deficits resulting from beatings, peptic ulceration, tissue damage caused by frostbite, nutritional deficiencies with muscle wasting, a wide range of infectious diseases, and heavy metal poisoning.

For long-term hostages the demands of re-entry into society are heavy and prolonged, and in some respects similar to individuals released from any longterm imprisonment. The 'settling down' stage is associated with a range of psychological, emotional and somatic problems, and suicide has been reported during this phase and in those who endured prolonged torture. Over the first year optimism tends to wane, and feelings of perplexity, lack of involvement, and loneliness increase. Much of the first year can be spent attempting to find accommodation, securing financial resources and obtaining employment. During this period family support is particularly important (Ekland-Olson et al, 1983).

Post-traumatic stress disorder (PTSD) has been described in hostages and victims of torture (Corrado \& Tompkins, 1989; Allodi, 1994). Incomplete emotional processing, depressive reactions secondary to loss and adverse life events, somatoform symptoms and effects upon personal meanings and value systems are four common elements in reactions to torture which lead to further difficulties (Turner \& Gorst-Unsworth, 1990). A post-concentration camp syndrome has been described in survivors of Nazi camps, comprising symptoms of post-traumatic stress disorder (Ostwald \& Bittner, 1968) and a severe and pervasive depression, moroseness, withdrawal and apathy (Krystal \& Niederland, 1968).

Although it is natural to focus on the problems encountered after a hostage experience, it should 
lable 2. I samples of difficultien faced be houtages after release

\begin{tabular}{|c|c|c|}
\hline Time & Common & Possible \\
\hline $\begin{array}{l}\text { Early } \\
\text { (first few } \\
\text { days) }\end{array}$ & $\begin{array}{l}\text { Elated mood; emotional lability; overtalkativeness; overactivity; } \\
\text { optimism; feeling special; tension; tiredness; nightmares; nervousness; } \\
\text { phobias; vague physical complaints; insecurity; feeling misunderstood; } \\
\text { preoccupation with event; indecisiveness; guilt: (a) for leaving others } \\
\text { behind, (b) for surviving, (c) for behaviour towards others in order to } \\
\text { ensure own survival, (d) for not being more heroic (John Wayne Syndrome } \\
\text { injuries; infectious diseases; untreated illnesses (physical and psychiatric); } \\
\text { nutritional deficits; dental problems; difficulty relating to loved ones; media } \\
\text { pressure/interference }\end{array}$ & $\begin{array}{l}\text { Persisting Hostage } \\
\text { Identification } \\
\text { syndrome }\end{array}$ \\
\hline $\begin{array}{l}\text { Intermediate } \\
\text { (weeks or } \\
\text { months) }\end{array}$ & $\begin{array}{l}\text { Anxiety; tension; sleep difficulties; substance misuse; feeling lonely; } \\
\text { headaches; intestinal symptoms; rheumatic complaints; eczema; sexual } \\
\text { problems; persisting effects of injuries, e.g. epilepsy or other neurological } \\
\text { damage from beatings; persisting infectious diseases; financial changes; } \\
\text { marital problems; employment problems; problems with children; } \\
\text { difficulties readapting to social conventions; stigmatisation or } \\
\text { discrimination }\end{array}$ & $\begin{array}{l}\text { PTSD and other } \\
\text { psychological } \\
\text { states precipi- } \\
\text { tated by trauma } \\
\text { e.g. anxiety states, } \\
\text { depression, obse- } \\
\text { ssive-compulsive } \\
\text { disorder }\end{array}$ \\
\hline $\begin{array}{l}\text { Late } \\
\text { (months or } \\
\text { years) }\end{array}$ & $\begin{array}{l}\text { As above; reducing optimism; continuing readjustment to both positive } \\
\text { and negative changes }\end{array}$ & $\begin{array}{l}\text { Pervasive mo- } \\
\text { roseness and } \\
\text { depression; } \\
\text { apathy; with- } \\
\text { drawal; suicide }\end{array}$ \\
\hline
\end{tabular}

be noted that many describe positive benefits which may increase over time (Box 2).

\section{Specific reactions}

\section{Hostage identification syndrome (Stockholm syndrome)}

The Stockholm syndrome (perhaps best regarded, like the John Wayne syndrome described below, as a phenomenon rather than a syndrome) was named after an incident which took place during the robbery of a Stockholm bank in 1973. Four employees were held, and a female hostage developed a sexual relationship with a robber, and after release became engaged to marry him. The hostages feared the police more than their captors.

During an intense, life-threatening period of captivity when feelings of terror and helplessness predominate, hostages may occasionally regard the captor with gratitude for sparing their lives. Conversely they may regard the rescuing authorities with suspicion and fear, particularly when the demands of the captor are denied, thus adding to the peril of the situation. Positive feelings from the captor towards the hostages may occur and be well developed by the third day. There is a mutual understanding that the survival of both parties depends upon how the authorities choose to resolve the standoff and that, to some extent, the predicament is shared between the hostage and the

Box 2. Reported positive after-effects of the hostage experience

Closer relationships

Improved understanding of other cultures

Improved perspective on life

More emotional involvement

Conscious enjoyment

Cherished freedom

Stronger religious faith and enhanced personal values

Increased insight

Increased assertiveness

Enhanced self-esteem and self-understanding

Greater patience

Friendships born out of adversity

(van der Ploeg \& Kleijn, 1989; Easton \& Turner, 1991). 
captor. The development of these attachments is usually regarded as making it more difficult for the captor to kill the hostage, thus proving advantageous to the hostage but problematical for the captor.

Under certain circumstances, factors which contribute to the development of the hostage identification syndrome (HIS) can be manipulated by negotiators to attempt to improve the outcome (Wesselius, 1982). Sophisticated hostage-takers are aware of these possibilities, and therefore take precautions to inhibit the development of positive attachments by placing hoods over the heads of hostages to prevent eye contact, imposing silence, placing them in isolation, employing torture, and rotating guards frequently. Phalen \& Fergin (1978) describe systematic attempts by Japanese Red Army terrorists to manage hostage attitudes aboard an aircraft, demonstrating the extent to which preparations can be made prior to taking hostages.

Turner (1985) points out that the HIS does not always work in favour of the hostage, and can lead to a dangerous escalation of violence.

Hostage D, a 5-year-old girl, having looked into her captor's eyes could not believe that he would hurt her. She later watched as her smiling captor shot her repeatedly in the abdomen. She survived. (Ayalon, 1982)

\section{The John Wayne syndrome}

Commonly ex-hostages feel continuing responsibility towards those who shared their ordeal but who remain incarcerated, guilty about their own behaviour during captivity, and guilty for surviving when others have not. These feelings can be strong. They may appear irrational, but often reflect the ex-hostage's evaluation of his captor's state of mind.

On release Hostage $\mathrm{E}$ was very concerned that the media should not broadcast any statement of his which could be misinterpreted by his ex-captors as critical of them. He feared reprisals against his friends who remained in captivity. When a senior physician described on the national news the hostage's delight at seeing the colours of fresh fruit he became angry and dismayed. The physician was physically menaced by one of the hostage's associates.

When ex-hostages feel guilty for not having attempted some heroic act in order to protect or save others this has been called the John Wayne syndrome (Hatcher, 1987). It is usually accompanied by feelings of weakness. Ayalon (1982) observed that those who appear to have most guilt escape from terrorist situations unharmed. Severely injured victims can show considerable hostility directed not towards terrorists responsible for their injuries but rather towards society, social agencies or friends who abandon them. The partially injured appear to have least difficulty adapting psychologically. Ayalon attributes this to the capacity which the injury has in serving to 'absolve' them from the guilt of being unharmed, or serving as an 'atonement' to God, as if they had paid their price and could now feel exempt from additional harm.

\section{Management}

\section{Problems in immediate management}

Some survivors, families and communities reject offers of help out of hand, believing that release resolves all difficulties. These powerful attitudes inhibit sufferers from obtaining help. Other communities stigmatise survivors, scapegoat them, or envy any privileges which may accrue from their ordeal. Despite these reactions it remains important to provide information about possible psychological difficulties, contact addresses of helping organisations, and to keep offers of help open.

The provision of post-release support varies greatly between countries, the offer of after-care depending more on nationality than any other factor. In most countries there is no planned response available for released hostages - they simply return home and request help if they develop problems. Within Britain help has been offered on an unpredictable basis. Three Lebanese ex-hostages released in 1991 received considerable support, whereas another hostage released from two years in Iraq received only the taxi fare home from Heathrow airport. There have been recent calls in Britain for coordinated help to be available for released hostages, leading to the Hostage Recovery Bill being read before the House of Commons in March 1996 by the Labour MP for Walthamstow (Table 3).

Post-release management strategies depend upon many factors. For instance, the help given to a large number of uninjured aircraft passengers held for a few hours requires a different approach to the management of individuals held for years, who have become household names and who have been used as pawns in major international political affairs. Appropriate methods for both situations are described below.

\section{Low-level early help for brief situations and multiple hostages}

An effective, well-received system of management for several hundred people taken hostage by South 
Table 3. Support which should be available. At the earliest practical time the Secretary of State should advise the hostage and the hostage's parents, spouse and dependents of access to advice and assistance with regard to the following

Hostage

Necessary financial assistance to travel home

Immediate temporary accommodation

Claims of due benefits payments

Medical examinations

Psychiatric treatment

Requests for interviews or publicity from the media

Claims for compensation against other parties in connection with captivity or imprisonment

Appropriate services which may be available from statutory and non-statutory agencies

Such other matters as the Secretary of State may provide
Parents, spouse, dependents

Legal advice concerning the hostage

Claims of due benefits payments

Psychiatric counselling

Requests for interviews or publicity from the media

Claims for compensation against other parties in connection with captivity or imprisonment

Appropriate services which may be available from statutory and non-statutory agencies

Such other matters as the Secretary of State may provide

Summarised from Hostage Recovery Bill, read before House of Commons by Neil Gerrard MP on 13 March 1996

Moluccans was developed in Holland during the 1970s (van der Ploeg \& Kleijn, 1989). Taking an active but unobtrusive approach, ex-hostages and their families were contacted by a multidisciplinary outreach team shortly after release. They subsequently received a home visit and were offered further group meetings.

At group meetings information about possible psychological sequelae was provided. It was emphasised that individuals would react differently, that talking about the experience could bring benefits, that families would have different thoughts and feelings to ex-hostages, and that the stresses and strains experienced should not be regarded as signs of mental illness but understandable reactions to the event. Strategies to cope with the media were given, and details of organisations which could offer further help distributed. In most cases a second contact by telephone or home visit was made after a few weeks. General practitioners (GPs) received written information on how to approach and help hostage victims, and were asked to visit the victim, or victims were asked to visit them. Analysis of the effectiveness of this intervention demonstrated that:

(1) the offer of help was greatly appreciated by $85 \%$ of hostages and $96 \%$ of relatives, although a small proportion of ex-hostages wished that they had been left to contact helping agencies themselves;

(2) the amount of negative after-effects six to nine years after the event was significantly less in the group which received outreach help compared with those left to ask for help themselves;

(3) those initially approached by their GP did better than those approached by other workers;
(4) the timing of the offer of help was important, with delays of over four weeks being significantly associated with poorer outcomes many years later. However, it was also possible for treatment to be offered too early, thus suggesting that hostages needed time to themselves or with their families before engaging in treatment plans. Receiving an offer of help towards the end of the first week after release seemed about right.

This outreach strategy was simple, sensitive to the individual's wishes, beneficial and popular. In contrast, imposed treatments may not be well received, leading to passive participation and resentment (Bisson \& Deahl, 1994).

\section{Intensive, immediate help for long- term, high-profile hostages}

The release of individual hostages after years of captivity demands a different approach to that described above. In the recent past British hostages have received assistance from Royal Air Force psychiatrists and nurses, who have developed experience and a degree of expertise in the immediate post-release management of hostages and their families. The principles employed by the Royal Air Force are outlined below.

\section{Psychiatric teams}

A team of trained, selected and compatible individuals should be well briefed and on standby for the release of the hostage(s), and meet with family members before release to discuss potential difficulties, explain and engage them in the 
treatment process, and to identify those who will accompany the team during hostage collection and on to the protected surroundings immediately after release.

The minimum composition of a treatment team was a consultant psychiatrist as team manager and supporter for the therapist, a therapist (psychiatrist) for the hostage and family members, and a supporter who took responsibility for practical arrangements. However, when resources permitted, a primary team consisted of additional psychiatric nurses as therapists for family members, and was supported by a secondary team of psychiatrists and psychologists. As the trauma story can have a profound effect upon therapists (Talbot, 1990; McIvor \& Turner, 1995) such support teams have a valuable role to play in enabling the primary treatment team to function effectively.

\section{Controlling the post-release environment}

Substantial difficulties can arise from a continuing stream of interruptions (Karson, 1981). In particular, the media will attempt repeatedly and resourcefully to gain access to the hostage for photographs and interviews (McDuff, 1992). Such disruptions also come from numerous individuals and groups rightly interested in meeting the exhostage in order to celebrate the release - friends, former hostages, work colleagues, employers, politicians and pressure group leaders for example, but also government departments interested in gathering intelligence.

Hostage F, a 44-year-old man who had been kept chained and hooded for nearly 7 years, had never seen his 6.5-year-old daughter until he was released. A safe house had been prepared for him immediately after medical examinations were completed so that he could spend time with his family. However, this plan broke down when he was asked to switch on the Christmas tree lights in Washington by the American President, and to attend a series of celebratory ceremonies by those who had campaigned for his release.

The immediate post-release environment requires careful planning. A gatekeeping function should be established from the outset, to minimise unnecessary intrusions and maximise the possibility for the hostage to spend uninterrupted time with those most important to him.

\section{Immediate needs}

When a situation of protected privacy is secured, the immediate needs of the hostage can be addressed. A thorough medical, dental and psychological assessment is required, but simple material needs (e.g. clothing, writing materials, a watch) and requests for information should be anticipated. Full treatment facilities should be available, and assessment procedures coordinated to permit this aspect of early management to progress smoothly. It is helpful for intelligencegathering interviews by the authorities to take place in the presence of the psychiatrist who is therapist to the hostage, in order to support the hostage and permit the gathering of useful information, thus reducing the need for the hostage to repeat details of the history unnecessarily.

\section{Principles of treatment}

The principles of the psychosocial treatment of long-term, high-profile hostages have been described by Fletcher \& Craig (1992) and by the Psychiatric Division of the Royal Air Force Medical Branch (1993). The problems of relatives should be taken into account when formulating treatment plans. Severe physical or mental illness will take priority over other interventions in the first few days or weeks after release.

\section{Developing priorities}

During early readjustment there are many important decisions to be made when the hostage is least able to make them. For some, their status in life will have been irreversibly changed, either as a result of losses or following honours and rewards in recognition of their suffering and endurance. There is a need for sensible priorities and guiding principles to be set, and these can be developed in discussion with the hostage and those closest to her or him. The necessity and value of re-establishing solid and lasting relationships in order to provide a supportive social network during rehabilitation should be emphasised, as well as the benefits of gaining secure employment rather than relying on unpredictable opportunities to make money from recounting experiences. Ideally, the timing of a return to work should be determined by the individual's readiness, but may in fact be governed by demands from others or financial necessity.

\section{Picking up the threads}

Re-establishing close, stable relationships is complicated by many factors. There are often changes to the immediate family resulting from bereavements or the addition of new members by marriage or birth. Relatives may be reluctant to 
discuss or impart bad news, because of concerns for the hostage's well-being, uncertainties over their psychological stability, or because it does not seem appropriate at a time of rejoicing to talk about distressing events. These concerns block the process of open exchange and inhibit the development of emotional closeness. Both hostages and relatives wish to talk about significant issues, but are afraid to do so. Judicious and gentle exposure to these issues improves the process of clarification and mutual understanding, effectively opening up the possibilities for intimacy and a sense of reconciliation. In practice this can be achieved by daily individual interviews with the hostage and each family member, during which concerns are explored, followed by family meetings in which those concerns are voiced and addressed. This process requires care and skill, but results in rapid and rewarding progress.

\section{Preparation for the future}

Towards the end of treatment the hostage and relatives may be concerned about their ability to manage without close support. It is appropriate to ask them to address potential future difficulties which may not be anticipated: coping with changes in status; persisting media and public attention; continuing demands for experiences to be recounted; frequent social invitations with possible associated excessive alcohol intake; deciding where to live; adjusting to normality after a period of prominence; accepting the fact that nobody can accurately understand what they have been through. The emphasis during this stage of management is on assisting the hostage and his or her relatives to develop and rehearse problemsolving strategies, thus helping them to gain confidence.

\section{Psychiatric treatments}

Following the psychiatric assessment, treatment of any disorder should be provided using standard approaches (see Adshead (1995) for the treatment of post-traumatic psychological problems). However, the hostage should also be given the opportunity to tell their story, as this can enable them to gain a different perspective of the ordeal, feel supported, identify important issues which need to be dealt with, and to concentrate on the future rather than the past.

Assuming that there are no serious physical or psychiatric illnesses, immediate intensive postrelease management should be brief, the duration ranging from 10 days to three weeks. Termination is governed by the completion of necessary tasks and the confidence of the hostage and his immediate relatives in their ability to cope on their own. The approach adopted by the Royal Air Force proved constructive in helping hostages negotiate the first stage of readjustment.

\section{Conclusions}

The post-release management of hostages requires the flexible employment of multidisciplinary skills, sometimes under difficult and changing circumstances. There are physical, psychological, social and spiritual dimensions to recovery, and multidisciplinary management should reflect this and not be restricted to the narrow limits of psychological disorder. Although early help is beneficial full recovery may take many years, throughout which assistance with continuing social problems and compensation issues may be necessary. However, local help is often unavailable, partly because professional carers feel ill-equipped to deal with ex-hostages. Under these circumstances, support from other former hostages can play a particularly important role.

Post-release management and support for hostages is a current political issue. A recent conference on the Medical Aspects of Terrorism in London has highlighted the need for necessary expertise to be fostered. The reading of the Hostage Recovery Bill has stimulated Government interest and is making assistance available in a reliable and coordinated way.

\section{References}

Adshead, G. (1995) Treatment of victims of trauma. Advances in Psychiatric Treatment, 1, 161-169.

Allodi, F. A. (1994) Post-traumatic stress disorder in hostages and victims of torture. Psychiatric Clinics of North America, 17, 279-288.

*Anderson, T. A. (1993) Den of Lions: Memoirs of Seven Years, pp. 98-99. New York: Crown Publishers.

*Ayalon, O. (1982) Children as hostages. The Practitioner, 226, 1773-1781.

Bisson, J. I. \& Deahl, M. P. (1994) Psychological debriefing and prevention of post-traumatic stress. British Journal of Psychiatry, 165, 717-720.

Corrado, R. R. \& Tompkins, E. (1989) A comparative model of the psychological effects on the victims of state and anti-state terrorism. International Journal of Law and Psychiatry, 12, 281293.

Easton, J. A. \& Turner, S. W. (1991) Detention of British citizens as hostages in the Gulf - health, psychological, and family consequences. British Medical Journal, 303, 1231-1234.

Ekland-Olson, S., Supancic, M. \& Campbell, J. (1983) Postrelease depression and the importance of familial support. Criminology, 21, 253-275. 
Fletcher, K. D. \& Craig, K. D. (1992) The management of hostages after release. In Stress, Psychiatry and War, pp. 179-182. World Psychiatric Association.

Goldberg, D. P. \& Hillier, V. F. (1979)Ascaled version of the general health questionnaire. Psychological Medicine, 9, 139-145.

Hatcher, C. (1987) A conceptual framework in victimology: the adult and child hostage experience. In Contemporary Research on Terrorism (eds P. Wilkinson \& A. M. Stewart), pp. 357-376. Aberdeen: The University Press.

*Hillman, R. G. (1981) The psychopathology of being held hostage. American Journal of Psychiatry, 138, 1193-1197.

Horowitz, M. J., Wilner, N., Alberez, W. (1979) The impact of events scale: a measure for subjective stress. Psychosomatic Medicine, 41, 209-218.

Karson, S. (1981) The return of our American hostages: a psychologist's experience. American Psychologist, April, 420-421.

Krystal, H. \& Niederland, W. G. (1968) Clinical observations on the survivor syndrome. In Massive Psychiatric Trauma (ed. H. Krystal), pp. 327-348. New York: International University Press.

McDuff, D. R. (1992) Social issues in the management of released hostages. Hospital and Community Psychiatry, 43, 825-828.

McIvor, R. J. \& Turner, S. W. (1995) Assessment and treatment approaches for the survivors of torture. British Journal of Psychiatry, 166, 705-711.

Ostwald, P. \& Bittner, E. (1968) Life adjustment after severe persecution. American Journal of Psychiatry, 124, 87-94.

Phalen, T. \& Fergin, G. G. (1978) Terrorism: a hijacking and a coup. Department of State Newsletter, January, pp. 8-14.

Psychiatric Division of the Royal Air Force Medical Branch (1993) The management of hostages after release. Psychiatric Bulletin, 17, 35-37.

Siegel, R. K. (1984) Hostage hallucinations. Journal of Neroous and Mental Disease, 172, 264-272.

Stöfsel, W. (1980) Psychological sequelae in hostages and the aftercare. Danish Medical Bulletin, 27, 239-241.

Talbot, A. (1990) The importance of parallel process in debriefing crisis counsellors. Journal of Traumatic Stress, 3 , 265-277.

*Turner, J. T. (1985) Factors influencing the development of the Hostage Identification Syndrome. Political Psychology, 6, 708711.

Turner, S. \& Gorst-Unsworth, C. (1990) Psychological sequelae of torture - a descriptive model. British Journal of Psychiatry, $157,475-480$.

"van der Ploeg, H. M. \& Kleijn, W. C. (1989) Being held hostage in The Netherlands: a study of long-term after effects. Journal of Traumatic Stress, 2, 153-169.

Weschler, L. (1990) A Miracle, a Universe: Settling Accounts with Torturers, pp. 146-147. New York: Pantheon Books.

"Wesselius, C. L. (1982) Psychological aspects of hostage negotiations and response. The Practitioner, 226, 1784-1789.

* indicates articles of particular interest

\section{Multiple choice questions}

1. During brief captivity, the following commonly occur:
a the Hostage identification syndrome
b autonomic hyperarousal
c waves of terror
d psychotic reactions
e suicide attempts.

2. After release the following problems occur in the majority of cases:
a post-traumatic stress disorder
b marital difficulties
c anxiety symptoms
d preoccupation with the event
e failure to make a full readjustment.

3. The following factors can increase the development of the Hostage identification syndrome:
a. eye contact with the captor
b imposed silence
c the use of hoods
d personal conversation between hostage and captor
e changing guards.

4. Management of multiple, briefly-held hostages:

$a$ is effective when given by GPs

b involves routine intensive counselling

c does not need to involve relatives

d using an outreach approach is commonly resented

e should involve advice about handling the media.

5. In the management of long-term, high-profile hostages:

a a protected environment is not essential for treatment

b unusual physical conditions should be searched for

c the main focus of treatment is the hostage's psychological state

d prior relationships may be difficult to reestablish

e psychological disorder is almost inevitable.
MCQ answers

\begin{tabular}{|c|c|c|c|}
\hline 1 & 2 & 3 & \\
\hline$F$ & a $F$ & a & $T$ \\
\hline $\mathbf{T}$ & b F & b & $\mathbf{F}$ \\
\hline $\mathrm{T}$ & c $\mathrm{T}$ & F & \\
\hline $\mathbf{F}$ & d $T$ & d & \\
\hline F & e $F$ & e $\mathrm{F}$ & \\
\hline
\end{tabular}

